\title{
PAUL RICGEUR: A RECUSA DO MODELO DIALOGAL NA HERMENÊUTICA
}

\author{
Luisa Nogueira
}

"Hermeneutics begins where dialogue ends"

Paul Ricœur

\section{Introdução}

No decurso la leitura da obra de Ricœur, principalmente após a sua viragem hermenêutica, surgiu-nos a questão de como interpretar o facto de serem tão escassas as referências:

- ao "diálogo" nos termos em que Gadamer o coloca (na sequência do questionamento socrático);

- à "lógica pergunta-resposta", ou à dialéctica pergunta-resposta, estruturante do fenómeno hermenêutico segundo Gadamer.

Esta questão torna-se mais pertinente quando nos damos conta, simultaneamente, da importância que Ricœur concede à obra de Gadamer na organização da sua proposta hermenêutica e da "primazia hermenêutica da questão"l em Wahrheit und Methode. O projecto de Gadamer, na sequência directa da hermenêutica heideggeriana, aparece-lhe como incontornável: a - bra de Gadamer está presente principalmente em Herméneutique, Du texte à l'action e Temps et récit $I I P$. Ricœur refere frequentemente Wahrheit und Methode e adopta (e adapta) alguns conceitos tais como: "jogo" e "metamor-

1 Título do último dos subcapítulos do capítulo 3, Secção II, da obra de Gadamer Wahreit und Methode. A longo do nosso artigo utilizaremos a tradução castelhana desta obra: Verdad y método, tradução de Ana Agud Aparício e Rafael de Agapito, Edicienes Sigueme, Salamanca, 1977.

2 RICCEUR, Herméneurique, Curso de 1971-1972 Louvaina, Éditiens du SIC, Institut Supérieur de Philosophie, s.d.; Du texte à l'action. Éditions du Sevil, Paris 1986; Temps et récit III. Éditions du Seuil, Paris, 1985. 
fose" (principalmente em Herméneutique), "coisa do texto" e "fusão de horizontes" (principalmente em Du texte à l'action), "consciência da história dos efeitos", (principalmente em Temps et récit III). Quanto ao conceito de "diálogo", encontramos várias referências no texto de Ricœur, mas notamos que não só não aparece claramente numa relação com o texto de Gadamer, como ainda o sentido que lhe é dado não é de modo algum equivalente ao sentido que lhe é dado por Gadamer. No que se refere à "lógica pergunta-resposta", encontramos referências explícitas principalmente em Temps et récit III, mas num contexto em que é destituída do peso e alcance que assume na teoria hermenêutica de Gadamer.

Assim este artigo visa:

- apresentar as razões que justificam a desvalorização do diálogo na hermenêutica de Ricoeur

- mostrar, aquilo a que podemos chamar, os equívocos da sua concepção de diálogo

- dar conta de uma perplexidade: como compreender o esquecimento, a este nível, das concepções de Gadamer

- justificar a recusa do modelo dialogal na hermenêutica de Ricoeur, à luz da pretensão epistemológica e da dimensão reflexiva da sua hermenêutica

- apresentar a leitura como substituindo o diálogo no processo hermenêutico e esclarecer a sua função.

\section{§ 1. Diálogo e oralidade}

Tanto a teoria do texto alicerçada na autonomia semântica, à época de Du texte à l'action, como a teoria do texto alicerçada na teoria da mimesis, à época de Temps et Récit, estão associadas a uma desvalorização da situação dialogal e do modelo dialogal para a hermenêutica. Isso acontece ora por oposição à escrita e ao distanciamento que ela supõe, ora por oposição à situação de leitura.

Tomando como um dos eixos estruturantes da teoria hermenêutica de Ricœur a dialéctica evento-significação do discurso e a dialéctica sentido-referência, vemos que tanto a teoria do texto como a concepção de diálogo lhe estão subordinadas. Vejamos como a questão se coloca do lado do diálogo: situado no campo da oralidade, da "conversação", da "fala", comprometido com a situação da presença e da contemporaneidade dos interlocutores, será associado ao carácter de evento do discurso e à imediatidade da compreensão. Pelas mesmas razões será limitado à referência ostensiva. A imediatidade e a simplicidade caracterizariam a situação de diálogo, em oposição ao que se passaria na escrita, no texto/obra e na interpretação textual. A 
"estreiteza da situação dialógica"3 só poderia ser ultrapassada pelas referências que o texto abre: pela interpretação do "mundo do texto" (a expressão "mundo do texto" é o que equivale, segundo Ricœur, à "coisa do texto" em Gadamer) ${ }^{4}$.

Referindo-se ao modo como o trabalho de interpretação se exerce ao "nível mais elementar e mais banal da conversação" (sublinhado nosso), afirma que ele ocorre "numa troca concreta de mensagens entre os interlocutores e cujo modelo é o jogo da pergunta e da resposta"5. O "jogo", a "troca" de perguntas e de respostas é o que define o diálogo mas no âmbito da copresença dos interlocutores. Por essa razão, afirma Ricœur, na "situação simples do diálogo, explicar e compreender recobrem-se pouco mais ou menos. Quando não compreendo espontaneamente, peço-vos uma explicação; a explicação que me dais permite-me compreender melhor. A explicação não é senão uma compreensão desenvolvida através de perguntas e respostas" (sublinhado nosso) ${ }^{6}$. Esta possibilidade decorre naturalmente do facto da intenção subjectiva do falante e da significação se recobrirem naquilo que Ricœur considera ser a imediatidade do diálogo. Na situação do diálogo oral a explicação não seria senão a compreensão desenvolvida por questões e respostas. Note-se que a explicação seria apenas uma explicitação da compreensão e, mais do que isso, o perguntar apenas visaria o esclarecimento da intenção do interlocutor que "responde". Definido o diálogo nesta base, torna-se claro que a escrita quebra esta imediatidade e esta simplicidade através da tripla autonomia do texto e que o diálogo não pode ser o modelo da actividade interpretativa reduzida a uma explicitação de uma intenção subjectiva.

A concepção de diálogo em Ricœur aparece no contexto da oralidade,

${ }^{3}$ Cf. RICEUR, Du texte à l'action, p. 189.

${ }^{4}$ Citamos, a título de exemplo: "Prenant toujours pour guide les catégories de l'herméneutique générale, j'aborde maintenant la catégorie que j'ai appelée la 'chose du texte' ou le 'monde du texte'. Je puis dire que c'est la catégorie centrale, aussi bien pour l'herméneutique philosophique que pour l'herméneutique biblique. (...) La 'chose' du texte, voilà l'objet de l'herméneutique. Or la chose du texte, c'est le monde qu'il déploie devant lui." RICCEUR, Du texte à l'action, pp. 125-126.

5 "Il importe donc de préciser pourquoi l'herméneutique a un rapport privilégié avec les questions de langage. Il suffit, me semble-t-il, de partir d'un caractère tout à fait remarquable des langues naturelles, qui appelle un travail d'interprétation au niveau le plus élémentaire et le plus banal de la conversation. (...) Mais le maniement des contextes, à son tour, met en jeu une activité de discernement qui s'exerce dans un échange concret de messages entre les interlocuteurs et dont le modèle est le jeu de la question et de la réponse." RICEEUR, Du texte à l'action, pp. 76-77.

6 "Dans la situation simple du dialogue, expliquer et comprendre se recouvrent à peu près. Quand je ne comprends pas spontanément, je vous demande une explication; l'explication que vous me donnez me permet de mieux comprendre. L'explication n'est qu'une compréhension devélopée par questions et réponses" Ibidem, p. 165. 
da presença dos interlocutores, o que podemos considerar como o primeiro equívoco. Se é clara no texto de Ricœur a identificação entre a situação dialógica e a situação de comunicação oral, essa identificação não é, de modo algum, necessária. Verificamos no texto de Gadamer que não há implicação necessária entre diálogo e oralidade e que o "jogo da pergunta-resposta" que define 0 diálogo, não se restringe à relação directa e presencial nem está comprometido com um encontro entre subjectividades.

Vemos em Wahrheit und Methode que é a partir da referência à dialéctica platónica e ao diálogo socrático que Gadamer clarifica os pressupostos do conceito de diálogo na hermenêutica e que considera que o "fenómeno hermenêutico encerra em si o carácter original do diálogo e a estrutura da perguntas e da respostas"7. Se Ricœur lê o fenómeno hermenêutico a partir do texto e da escrita, Gadamer fá-lo a partir do diálogo e da estrutura pergunta-resposta que o constitui.

Referindo-se à situação do diálogo socrático, considera Gadamer: "o que ressalta na sua verdade é o logos, que não é meu nem teu, e que por isso ultrapassa a opinião subjectiva dos companheiros de diálogo, a tal ponto que inclusivamente aquele que conduz o diálogo permanece sempre também ele, como o que não sabe"8. O que devemos registar relativamente à situação de diálogo não é ser um encontro face a face e muito menos de duas subjectividades, mas o facto de os interlocutores se situarem na busca de uma verdade, de um acordo relativamente ao tema em discussão. O tema, aquilo sobre que se fala, é que é o alvo do perguntar e do responder que define o diálogo e "tal como na conversação, a compreensão deve procurar reforçar o sentido do que é dito." . Que se possa compreender melhor um assunto através do diálogo oral, ou que a oralidade apresente uma expressividade e uma força ilocucionária que a escrita apesar de tudo não consegue, isso não está em discussão. Mas o que define o diálogo enquanto tal não é a situação de "conversação" mas aquilo que também aí se pode encontrar: a investigação de um tema através de um procedimento interrogativo, o único que deixa em aberto a possibilidade de continuar a interrogar e para o qual as posições fixas e cristalizadas representam apenas incapacidade dos interlocutores. Quando Gadamer afirma que "a tarefa hermenêutica se concebe como uma entrada em diálogo com o texto"10, não quer com isso dizer que se trata de um diálogo com o autor do texto, mas com aquilo de que fala o texto, a "coisa do texto". O objectivo do "diálogo" vai no sentido de compreender a questão para a qual o texto é uma resposta. A compreensão hermenêutica não se refe-

7 GADAMER, Wahreit und Methode, trad. castelhana, p. 447.

8 GADAMER, Wahrheit und Methode, trad. castelhana, pp. 445-446.

${ }^{9}$ Gadamer, Idem, pp. 473-474 .

10 Gadamer, Idem, p. 446. 
re "a uma relação entre pessoas, por exemplo entre o leitor e o autor (que pode ser totalmente desconhecido), mas a uma participação naquilo que é comunicado pelo texto"1. Neste contexto a afirmação de Ricceur de que "o diálogo é uma troca de perguntas e de respostas" e de que "não há troca desta espécie entre o escritor e o leitor"12, para além de dúbia, não serviria para invalidar o modelo do diálogo na hermenêutica mas apenas para invalidar o modelo da compreensão hermenêutica como compreensão da intenção do autor (que é, aliás, o que Ricœur acabará por fazer, como veremos). Ora, o modelo dialogal pode sustentar-se fora de qualquer perspectiva psicologista do compreender, tal como podemos verificar na hermenêutica de Gadamer.

O "diálogo com o texto" que, segundo Gadamer, "é algo mais do que uma metáfora, é a lembrança da situação original"13 não traz consigo qualquer visão nostálgica de uma oralidade impossível, nem quaisquer marcas de uma perspectiva psicológica do compreender, antes remete para o diálogo como o que corresponde à dimensão constitutiva do pensar e da sua comunicabilidade. A "dialéctica da pergunta e da resposta", que constitui a estrutura da experiência hermenêutica, "faz aparecer a compreensão como uma relação recíproca do género do diálogo"14 e não se define nem pela imediatez nem pela simplicidade, mas pelo movimento do perguntar e responder no âmbito de um tema - "a coisa do texto" - procurando a sua verdade. Na comunicação viva cada posição aparece como uma posição, que a presença dos interlocutores e o prosseguimento do diálogo (filosófico e não sofístico !) impede que se fixe e torne dogmática; se a escrita fixa o discurso e corre o risco de o fixar dogmaticamente, será a "arte da compreensão" que proporciona ao escrito a ajuda de que carece $^{15}$. Mas do ponto de vista da compreen-

36 Gadamer, Idem, p. 470.

12 Em Du texte à l'action, afirma Ricœur, a propósito da relação escrever-ler e autor-leitor: “Ce n'est pas un rapport d'interlocution; ce n'est pas un cas de dialogue. Il ne suffit pas de dire que la lecture est un dialogue avec l'auteur à travers son oeuvre; il faut dire que le rapport du lecteur au livre est d'une tout autre nature; le dialogue est un échange de questions et de réponses; il n'y a pas d'échanges de cette sorte entre l'écrivain et le lecteur; l'écrivain ne répond pas au lecteur; (...) Cette substitution de la lecture au lieu même où le dialogue n'a pas lieu est si manifeste que, lorsqu'il nous advient de rencontrer un auteur et de lui parler (par exemple de son livre), nous avons le sentiment d'un profond bouleversement de ce rapport si particulier que nous avons avec l'auteur dans et par son œuvre." ob. cit., p. 139.

13 GADAMER, Wahrheit und Methode, trad. castelhana, p. 446.

14 GADAMER, Wahrheit und Methode, trad. castelhana, p. 456.

15 Para Gadamer a "debilidade" do escrito "que necessita sempre da ajuda do seu autor, uma vez que não é capaz de se defender e socorrer a si mesmo" (PLATÃ̃O, Fedro 275 e, tradução portuguesa de Manuel Pulquério, Maria Teresa Schiappa de Azevedo e José Ribeiro Ferreira), ilustrada pelo mito de Teuth (Fedro 274d-275b) e na Carta VII, (341c-344e) de Platão, deve ser também interpretada à luz da sua própria obra e dos problemas hermenêu- 
são hermenêutica, e diferentemente de Ricœur, oralidade e escrita não têm que divergir: "Pode-se dizer que o diálogo escrito reivindica a mesma condição fundamental que a troca oral. Nos dois casos quer-se compreender (...). É assim que, onde quer que se procure a compreensão, encontra-se a boa vontade." 16

Para Ricœur o discurso oral parece inclusivamente não levantar questões hermenêuticas. A presença dos locutores, a situação comum que viabiliza o diálogo, a tendência à identificação entre o sujeito, o indivíduo e o discurso, entre quem diz, o que diz e o modo de dizer, com o concurso de todos os dispositivos gramaticais, emotivos e enfáticos que caracterizam a força ilocucionária e a expressividade da comunicação oral, fazem com que a distância entre o dizer e o dito se esbata continuadamente na sequência de um processo onde "compreender e explicar se recobrem mutuamente" 17 , o diálogo esclarece e elucida e, admite Ricœur: a palavra pode ainda ser "sincera e directa"18.

ticos que levanta. Afirma Gadamer: “(...) Quando ele requer a ajuda da dialéctica para socorrer esta fraqueza das palavras, e que declara desesperado o caso da escrita, trata-se evidentemente de um exagero irónico pelo qual oculta a sua própria obra literária e a sua arte pessoal. Na verdade, passa-se o mesmo tanto com a escrita como com o discurso oral. Encontra-se no discurso falado uma arte do simulacro e uma arte do pensamento verdadeiro, a sofística ao lado da dialéctica: a isto corresponde evidentemente um desdobramento da arte de escrever, cujas duas formas servem respectivamente as duas formas de pensamento. De facto, existe também uma arte de escrever capaz de "prestar socorro" ao pensamento; é a ela que é preciso ligar a arte de compreender, que presta o mesmo socorro ao que é escrito" (GADAMER, Wahrheit und Methode, trad. castelhana, p. 472). Notemos que na perspectiva de Gadamer, a posição platónica expressa nos textos acima referidos, não deve ser interpretada como um mero ataque à escrita, como interpreta Ricœur em Interpretation theory (pp. 38-40), mas principalmente à utilização do texto escrito.

16 GADAMER, Text und Interpretation, Ges.W. 2 Hermeneutik, II, p. 330-360, 1983, trad. francesa in Art de Comprendre, Écrits 2, Aubier 1991, p. 211.

17 RICEUR, Du texte à l'action, p. 165.

18 “(...) l'écrit s'arrache aux limites du dialogue face à face et devient la condition du devenir-texte du discours. Il revient à l'herméneutique d'explorer les implications de ce devenir-texte pour le travail de l'interprétation.

La conséquence la plus importante est qu'il est mis définitivement fin à l'idéal cartésien, fichtéen, et, pour une part aussi, husserlien, d'une transparence du sujet à lui-même. Le détour par les signes et par les symboles est à la fois amplifié et altéré par cette médiation par des textes qui s'arrachent à la condition intersubjective du dialogue. L'intention de l'auteur n'est plus immédiatement donnée comme veut l'être celle du locuteur dans une parole sincère et directe."RICEUR, Du texte à l'action, p. 31.

Para Ricœur uma das maiores consequências que decorrem da consideração do texto escrito como eixo da hermenêutica, diz respeito ao estatuto do sujeito, quer na forma do emissor (locutor/autor), quer na forma do receptor (interlocutor/leitor). Para Ricoeur, o desaparecimento do autor na obra e o desaparecimento da situação de diálogo exigem a reformulação das questões hermenêuticas e do ponto de vista filosófico significam na sua perspectiva a impossibilidade de um acesso a si não mediatizado. A comunicação do ponto de vista hermenêutico é um processo diferido e mediato. No entanto, a este respeito poderemos perguntar se Ricoeur não preserva a possibilidade de uma comunicação transpa- 
Note-se que a valorização do diálogo e da dialéctica pergunta-resposta em Gadamer, não têm como contrapartida a desvalorização do escrito e da leitura. A escrita revela a dimensão histórica do fenómeno hermenêutico e as diversas interpretações de um texto pertencem-lhe, não como algo de exterior e acrescentado, mas como aquilo que o constitui na sua verdade. A escrita revela a "idealidade da linguagem" porque "o sentido do que é falado está ali por si mesmo inteiramente livre de todos os momentos emocionais da expressão e da comunicação. Um texto não quer ser entendido como uma manifestação vital, mas unicamente a respeito daquilo que diz"'19. De qualquer modo a questão hermenêutica não é a da escrita ou a da fala, mas a da compreensão. Como afirma Gadamer: "a arte de escrever, tal como a de falar, não representam um fim em si e não são portanto objecto primário do esforço hermenêutico. A compreensão vê-se atraída por completo pelo assunto mesmo (...)" 20 . Em qualquer dos casos o que é visado é "o sentido do que é dito" e a eventual debilidade do escrito está compensada pela facilidade em separar o sentido relativamente ao autor. Se o diálogo oral exige interlocutores o texto escrito exige intérpretes mas, quer num caso quer noutro, a compreensão refere-se ao "sentido do dito" e a significação e a verdade a um acordo sobre o tema.

\section{§ 2. A oposição à hermenêutica romântica e a dialéctica entre explicar e compreender}

Os diferentes modos de conceber o diálogo, por parte de Ricœur e de Gadamer, situam-se no entanto no quadro de uma perspectiva comum relativamente à relação entre a compreensão e a interpretação. Segundo Ricoeur a compreensão como "qualquer projecção de sentido numa situação" acompanha pari passu a interpretação. Conceitos com idêntica extensão, também a compreensão é referida a um nível ôntico-existencial como pré-compreensão ontológica (seguindo Heidegger), ou preconceito (com Gadamer) e entendido como apropriação (designação com conotação existencial que Ricœur parece preferir a "aplicação") enquanto resultado da exegese. A compreensão hermenêutica começa por estar ligada ao compreender heideggeriano associado à situação hermenêutica do intérprete. A este nível Ricœur não diverge relativamente a Gadamer.

A recusa do modelo dialogal por parte de Ricœur surge claramente no contexto de oposição à hermenêutica romântica de Schleiermacher. A pers-

rente. Na oralidade permaneceria a possibilidade ideal de uma proximidade do sentido na presença do sujeito. A ser assim, a crítica da "consciência falsa" encontraria um limite na "palavra viva".

19 GADAMER, Wahrheit und Methode, trad. castelhana, p. 471.

20 GADAMER, Idem, pp. 473-474. 
pectiva da hermenêutica romântica que Ricoeur contesta é a que afirma, nas suas palavras, que "compreender seria estabelecer entre a alma do leitor e do autor uma comunicação, ou seja, uma comunhão semelhante à que se estabelece num diálogo face a face" 21 . Mas a partir do momento em que o diálogo é concebido por Ricœur nesta perspectiva - comunicação entre o autor e o leitor numa situação face a face - então ele terá que ser afastado exactamente na mesma medida em que o é a compreensão hermenêutica como processo psicológico. Comprometer o diálogo com o psicologismo é então o segundo equívoco. Neste contexto a recusa do diálogo e do modelo dialogal funciona como uma linha de completa oposição e distanciamento relativamente à hermenêutica romântica. É em nome da estrutura ontológica do compreender que Ricœur se afasta da hermenêutica romântica, arrastando no mesmo gesto o modelo dialogal. Mas, como vimos, tal como não há implicação necessária entre diálogo e oralidade, também não existe entre modelo dialogal e hermenêutica romântica. No entanto são estes os pressupostos que legitimam o modo como sistematicamente se refere ao diálogo principalmente em Interpretation theory e em Du texte à l'action. Sob este aspecto Ricœur parece esquecer o contributo de Gadamer e constrói a sua perspectiva hermenêutica situando-a principalmente entre a hermenêutica romântica e diltheyana por um lado e o estruturalismo por outro. Circunscrevendo o debate a duas grandes linhas em oposição, a sua perspectiva aparece como complementar, estabelecendo uma relação que considera "dialéctica" entre a atitude explicativa e a atitude compreensiva 22 .

Valorizando a escrita (em oposição à oralidade e ao diálogo), organizando a sua teoria do texto tendo por base a "autonomia semântica", Ricœur combate o psicologismo e a subjectividade mas, mais do que isso, concilia a "explicação" e a "compreensão", assegurando a dimensão epistemológica na hermenêutica. Deste modo ultrapassaria tanto a dicotomia diltheyana entre "compreensão" e "explicação" como a alternativa que lê no título da obra de Gadamer "Verdade ou método"23. Por outro lado, com a organização de uma teoria do texto assente numa teoria da escrita, Ricœur crê encontrar uma possibilidade de garantir a universalidade da hermenêutica ${ }^{24}$.

${ }^{21}$ Cf. RICCEUR, Du texte à l'action, p. 165.

22 “(...) Je ne considérerai de ce développement remarquable que ce qui concerne le débat entre expliquer et comprendre et je me concentrerai sur un seul exemple, celui du récit. (...) Ainsi, d'une part, au nom de l'objectivité du texte, tout rapport subjectif et intersubjectif serait éliminé par l'explication; d'autre part, au nom de la subjectivité de l'appropriation du message, toute analyse objectivante serait déclarée étrangère à la compréhension.

A cette mutuelle exclusion, $\mathrm{j}$ 'oppose la conception plus dialectique d'une interpénétration entre compréhension et explication." Ibidem, p. 165.

23 "La question est alors de savoir jusqu'à quel point l'ouvrage mérite de s'appeler: Vérité ET Méthode, et s'il ne devrait pas plutôt être intitulé: Verité OU Méthode" RICEUR, Du texte à l'action, p. 97.

24 "En revenant (...) a une problématique du texte, de l'exégèse et de la philologie, nous 
Segundo Ricœur os códigos que regulam a produção escrita exigem uma abordagem que não pode ter a situação de diálogo (na acepção de conversação associada à fala e à oralidade) como modelo e referência. É da especificidade da escrita que se regula por códigos distintos da oralidade que surge o universo dos textos que passa a poder interpretar-se também autonomamente. A legitimidade e necessidade da explicação justificam-se face à objectividade e ao carácter estruturado da obra, mantendo a compreensão tanto o significado de pré-compreensão e de projecção de possibilidades (seguindo Heidegger), como o de fusão de horizontes (seguindo Gadamer). Em qualquer dos casos um significado ontológico.

Para Ricœur a explicação não é relegada para um mero procedimento metodológico estranho à hermenêutica, mas passa a ser um momento indispensável e "necessário" do processo de interpretação, num mesmo "arco hermenêutico". A leitura estrutural não é apenas uma leitura inscrita nas possibilidades do texto e, muito menos, um "caso-limite por entre todas as possibilidades de considerar um texto" 25 como considera Gadamer; ela assume um carácter de necessidade no processo da compreensão hermenêutica. Este carácter "necessário" dos procedimentos explicativos deve ser precisamente associado a uma exigência da dimensão escrita dos textos, que é por sua vez o que sustenta a sua "tripla autonomia semântica". A explicação estrutural não é mais do que o tratamento dos textos como realidade absolutamente autónoma e a sua legitimidade e necessidade advêm da especificidade da escrita e da tripla autonomia do texto. É "a constituição do texto como texto e da rede de textos como literatura", que nada tem a ver com qualquer paralelo no universo do diálogo/conversação, que "autoriza" um comportamento explicativo em que os textos são considerados apenas como escrita (e não discurso), sem mundo (referência) e sem sujeito (quer sob a forma de autor quer sob a forma de leitor). O sentido do texto (que deve ser distinto da sua significação) emerge no seu espaço interno de oposições, semelhanças e diferenças. Qualquer proposta de análise textual, que abstraia do "sujeito" e do "mundo", sendo não só possível mas também necessária, não deixa de ser insuficiente: é o texto, concebido quer como rede de relações de sentido quer como projecção de um mundo, que exige tanto a abordagem explicativa quanto a sua superação pela abordagem compreensiva e propriamente her-

paraissons d'abord restreindre la visée, la portée, l'angle de vision de l'herméneutique. Mais comme toute revendication d'universalité est émise de quelque part, on peut attendre que la restauration du lien de l'herméneutique avec l'exégèse fasse apparaître à son tour des traits d'universalité que sans contredire vraiment l'herméneutique de Gadamer, la rectifient dans un sens décisif pour l'issue même du débat avec la critique des idéologies" RICCEUR, Du texte à l'action, pp. 365-366.

25 GADAMER, "Text und Interpretation", in Ges.W.2, Hermeneutik, II, p. 330-360, 1983; trad. francesa. L'Art de Comprendre. Écrits 2 Herméneutique et champs de l'expérience humaine, Éditions Aubier, Paris, 199, p. 209-210. 
menêutica. Na hermenêutica de Ricœur será o conceito de leitura (complementar do de texto) e não o de diálogo que permite suportar o jogo entre uma análise de textos que os considera como escrita "sem tempo", "sem mundo", "sem subjectividade" 26 , fora da sua condição de discurso e uma análise que o retoma como discurso, que o realiza como significação na apropriação que dele faz não apenas um leitor, não apenas um intérprete, mas principalmente um sujeito (tomado numa acepção psicológica, epistemológica e existen$\operatorname{cial}^{27}$ ). Será o conceito de leitura, complementar do de texto, que permite definir a interpretação como a dialéctica entre a compreensão e a explicação.

Ricœur começou assim por elaborar a sua proposta hermenêutica centrando-se numa teoria do texto que toma como ponto de partida a "autonomia semântica" e se associa directamente à natureza escrita do texto. Tendo afastado num primeiro momento o "sujeito", (quer na forma do autor, quer na forma do leitor), irá legitimar os procedimentos explicativos (o caminho da cientificidade, do rigor, o que Ricœur define como a "via longa") na hermenêutica. Mas ao pressupor a situação de ser-no-mundo originária e a historicidade de toda a compreensão, por um lado, e ao reclamar-se de uma filosofia da reflexão, por outro, Ricoeur considerou a insuficiência do momento explicativo no quadro de uma hermenêutica filosófica. Fazendo coincidir a hermenêutica com a reflexão, é o sujeito que encontramos como

26 “.....alors que les signes du langage renvoient seulement à d'autres signes à l'intérieur du même système et font que la langue n'a pas plus de monde qu'elle n'a de temps et de subjectivité, le discours est toujours au sujet de quelque chose: il se réfère à un monde qu'il prétend décrire, exprimer ou représenter (...)." RICEEUR, Du texte à l'action, p. 104.

27 Reunimos no conceito de "existencial" o sentido ético e o sentido ontológico que nos parece estar reunido em Ricœur no conceito de sujeito como "ipseidade". Reunimos o sentido ontológico do soi e a dimensão existencial (existencielle) do homem "agente e sofredor". O ponto de partida filosófico de Ricoeur é o da reflexividade enquanto modo de constituição do sujeito e o seu ponto de vista parece ser dominantemente antropológico em que o "sujeito" coincide com o "homem agente e sofredor". Esta expressão "I'homme agissant et souffrant" aparece repetidamente em Soi-même comme un autre, onde a hermenêutica é referenciada principalmente como, "herméneutique de l'existence", ou "herméneutique du soi". Citemos, do prefácio: "Sujet exalté, sujet humilié: c'est toujours, semble-t-il, par un tel renversement du pour au contre qu'on s'approche du sujet; d'où il faudrait conclure que le 'je' des philosophies du sujet est atopos, sans place assurée dans le discours. Dans quelle mesure peut-on dire de l'herméneutique du soi ici mise en oeuvre qu'elle occupe un lieu épistémique (et ontologique, comme on dira dans le deuxième étude) situé au-delà de cette alternative du cogito et de l'anti-cogito? (...) .....̀̀ la faveur de ce développement nouveau du thème de l'identité narrative, le concept d'action - dont, rappelons-le, le récit est la mimèsis - recouvrera l'amplitude de sens que pouvait avoir le concept aristotélicien de praxis, à l'encontre des délimitations drastiques - mais justifiées par le propos de l'analyse - auxquelles la sémantique de l'action aura soumis l'agir humain dans le sous-ensemble précédent. En même temps, et corrélativement, le sujet de l'action racontée commencera à s'égaler au concept le plus large de l'homme agissant et souffrant que notre procédure analytico-herméneutique est capable de dégager." RICCEUR, Soi-même comme un autre, p. 27 e p. 29. 
ponto de partida e de chegada. Simultaneamente, a legitimação dos procedimentos analíticos do ponto de vista de uma hermenêutica filosófica permitirá criar um campo de unidade onde a filosofia ainda se possa rever.

Se a questão hermenêutica em Ricœur for colocada em termos do seu projecto hermenêutico de raiz fenomenológica, pretendendo conciliar a "via curta" de Heidegger e também de Gadamer e a "via longa" do desvio pelos signos e pelas ciências da linguagem ${ }^{28}$, vemos que o afastar o diálogo do processo interpretativo vai a par da afirmação do carácter complexo das obras do discurso (em La métaphore vive ${ }^{29}$, Interpretation theory e em $D u$ texte à l'action) o que permite a abertura para a introdução da explicação semiológica num mesmo arco hermenêutico. A questão fundamental para Ricœur passa a ser a da articulação entre explicar e compreender cuja unidade (em termos de complementaridade e reciprocidade) vê ser possível numa hermenêutica centrada no texto e no trabalho de leitura. Paralelamente o modelo textual pode instituir-se como paradigmático relativamente à investigação nas ciências o que confere uma fecundidade e amplitude à hermenêutica do ponto de vista epistemológico que o modelo dialogal não permitiria.

As diferentes perspectivas de conceber o fenómeno hermenêutico, neste caso não tanto quanto à "compreensão" mas quanto à via pela qual ela se efectua, transparece, de modo significativo em nosso entender, no modo como os autores se referem ao "texto". Para Ricœur o "texto é mudo" e a "relação com o texto é uma relação assimétrica"30. Ora, para Gadamer, o texto fala ${ }^{31}$, e podemos considerar que o seu lugar está ao mesmo nível do intérprete. $\mathrm{Na}$ relação dialogal não há interlocutores privilegiados; é

${ }^{28} \mathrm{Em}$ Le conflit des interprétations, Ricœur propõe-se "substituer à la voie courte de l'Analytique du Dasein la voie longue amorcée par les analyses du langage". É deste modo que, continua Ricoeur: "garderons-nous constamment le contact avec les disciplines qui cherchent à pratiquer l'interprétation de manière méthodique et résisterons-nous à la tentation de séparer la vérité, propre à la compréhension, de la méthode mise en oeuvre par les disciplines issues de l'exégèse" RICEEUR, Le conflit des interprétations, p. 15.

29 RICEEUR, La Métaphore Vive, Éditions du Seuil, Paris, 1975.

30 "The text is mute. An asymmetric relation obtains between text and reader, in which only one of the partners speaks for the two." RICCEUR, Interpretation theory, p. 75.

31 Afirma Gadamer: "Mas eis a literatura: textos que não desaparecem, mas que se impõem com uma exigência normativa face a qualquer compreensão e precedem qualquer novo deixar-falar do texto. O que é que os distingue? Que textos possam assim permanecer (dastehen), o que é que isso significa para o discurso interpretativo?

A minha tese é a seguinte: é sempre na medida em que se retorna sobre eles que eles permanecem. Mas isso significa que eles produzem texto no sentido próprio e original. Palavras que não permanecem senão na medida em que se retorna sobre elas realizam por assim dizer por elas mesmas o verdadeiro sentido de um texto: elas falam." (sublinhado nosso). GADAMER, Text und Interpretation, Ges.W. 2 Hermeneutik, II, p. 330-360,1983, trad. francesa in Art de Comprendre, Écrits 2, Aubier 1991, p. 221. 
enquanto participante num tema comum e enquanto "resposta a uma pergunta" que o texto faz valer a sua pretensão à verdade ${ }^{32}$. Utilizando uma comparação que nos parece sugestiva, podemos dizer que, para Ricœur, o texto está para a hermenêutica tal como o facto para a ciência. Tal como o facto é construído (não existe facto bruto), também o texto é construído pela interpretação (não existe texto independentemente da interpretação e esta não se acrescenta ao texto como um apêndice extrínseco). A hermenêutica entendida como exegese textual é o trabalho sobre o texto com vista à compreensão, assim como a ciência é trabalho sobre os factos com vista à explicação. Assim como a validade da teoria se estabelece pela sua capacidade de integrar os factos, também a validade da interpretação se estabelece pela capacidade de integrar os elementos do texto numa totalidade coerente. Quer dizer, pela capacidade de reconstituir a sua "dinâmica interna" - o seu sentido -; e pela capacidade de o constituir como projecção de um mundo possível ${ }^{33}$.

Podemos dizer que, para Gadamer, o texto não é visto como um facto, mas como uma hipótese; é uma resposta para um problema, uma resposta possível. O sentido do texto deve ser procurado não no seu conjunto de enunciados, mas na questão para a qual estes constituem uma resposta. Não tem papel privilegiado enquanto solução, mas apenas enquanto resposta efectiva face ao conjunto de respostas possíveis. A hermenêutica tem assim por tarefa recolocá-lo no movimento vivo do questionar, em que o seu lugar seja o de interlocutor. Se ao ser visto como facto (ainda que construído), o texto apela à leitura, ao ser visto como hipótese ele exige ser recolocado no campo problemático para o qual se constituiu, ou se pode constituir, como resposta.

Para Gadamer a interrogação como via de acesso ao texto, traduz a nível da exegese a estrutura fundamental do fenómeno hermenêutico: a dialéctica pergunta-resposta. Como afirma Gadamer: "O começo aparentemente tético da interpretação, é na realidade uma resposta e, como em toda a resposta, também o sentido de uma interpretação se determina a partir da pergunta que é colocada. A dialéctica da pergunta e da resposta por consequência precedeu desde sempre a dialéctica da interpretação." 34

Para Ricœur a estrutura fundamental da hermenêutica é a da dialéctica

32 GADAMER, Wahrheit und Methode, trad. castelhana, p. 669; cf. igualmente p. 474.

33 "Une fois affranchie du primat de la subjectivité, quelle peut être la tâche première de l'herméneutique ? Elle est, selon moi, de chercher dans le texte lui-même, d'une part la dynamique interne qui préside à la structuration de l'œuvre, d'autre part la puissance de l'œuvre de se projeter hors d'elle-même et d'engendrer un monde qui serait véritablement la 'chose' du texte. Dynamique interne et projection externe constituent ce que j'appelle le travail du texte. C'est la tâche de l'herméneutique de reconstruire ce double travail du texte." RICCEUR, Du texte à l'action, p. 32.

34 GADAMER, Wahrheit und Methode, trad. castelhana, p. 565. 
pertença-distanciação dominada pelo facto da compreensão ser comunicação na e pela distância. A exegese textual torna produtiva esta distância através da análise da codificação textual e da colocação do sentido no presente do intérprete. Para Ricœur a "pertença" não pode ser considerada fora da sua relação dialéctica com a distanciação; a tradição engloba tanto a perspectiva da herança como a da crítica e da renovação; a "fusão de horizontes" como resultado da exegese, não traduz senão a dialéctica de toda a interpretação: a dialéctica entre o próximo e o distante. É através da teoria do texto, alicerçada no conceito de "distância" que introduz, aliás, a pressuposição fenomenológica de toda a hermenêutica, que Ricoeur pretende levar inclusivamente mais longe a posição de Gadamer. Se é verdade, como afirma Gadamer nas palavras de Ricœur, que a "experiência de linguisticidade não exerce a sua função mediadora senão porque os interlocutores do diálogo se apagam um e outro perante as coisas ditas que de qualquer forma conduzem o diálogo" 35 , então onde isso se realizaria de forma optimizada e sem quaisquer interferências ou ambiguidades seria no texto escrito. É a "coisa do texto" no dizer de Gadamer ou "o mundo" no dizer de Ricœur, que orientam o processo interpretativo. Sendo assim, o modelo do diálogo não seria necessário, podendo inclusivamente suscitar confusões e ambiguidades. O desenvolvimento de uma teoria do texto e o modelo do texto correlativo com o de leitura mostra-se, segundo Ricœur, mais eficaz e fecundo. Poderemos no entanto perguntar se a integração da lógica da pergunta - resposta gadameriana numa teoria da leitura entendida como "operação de refiguração" (mimesis III) e a nível de uma dialéctica material dos conteúdos, como acaba por fazer Ricœur ${ }^{36}$, a recusa do modelo dialogal para compreender o fenómeno hermenêutico em toda a sua extensão, não bastam para tornar difícil a compatibilidade entre a hermenêutica de Gadamer e a hermenêtica de Ricœur e inviabilizar a tentativa de a "rectificar"37. Trata-se, afinal, de concepções divergentes quanto à raiz do fenómeno hermenêutico.

\section{§ 3. Diálogo e dialéctica}

Como explicar o modo tão diferente de considerar o diálogo em Ricœur e em Gadamer? Se ligamos o diálogo ao processo de construção do saber, assumimos a sua raiz socrática, associamo-lo ao processo dialéctico de investigação e consideramos como subsidiária a sua dimensão comunicativa. O modo como Ricœur apresenta o diálogo, isto é, como relação simples,

35 "Mais l'expérience langagière n'exerce sa fonction médiatrice que parce que les interlocuteurs du dialogue s'effacent l'un et l'autre devant les choses dites qui en quelque sorte mènent le dialogue." RICCEUR, Du texte à l'action, p. 100.

36 Cf. RICCEUR, Temps et récit III, capt. IV.

37 Cf. RICCEUR, Du texte à l'action, pp. 365-366, cit. hic p. 10. 
imediata e directa entre interlocutores, evidencia a sua vertente comunicativa. O valor do diálogo, desligado de qualquer papel no processo de construção do saber, situa-se apenas a nível comunicativo; é mesmo nesta medida que o diálogo pertence à estrutura do discurso: "Um aspecto importante do discurso é que ele é dirigido a alguém. Há outro falante que é o endereçado do discurso. A presença do par, locutor e ouvinte, constitui a linguagem como comunicação.(...) Como Platão afirma, o diálogo é uma estrutura essencial do discurso" 38 .

Em Gadamer o que se evidencia no diálogo é uma investigação em comum acerca de um tema, uma atitude comum de procura de um saber que é ele mesmo de natureza dialéctica - discursiva e dialogal. Procura de um saber que não está constituído antes do diálogo mas que se constitui no e com o diálogo. É este que, através do questionar, separa no mesmo acto o saber do não saber. Afirma Gadamer: "Na medida em que uma pergunta põe a descoberto, ela inclui ao mesmo tempo os dois aspectos do juízo: o sim e o não. É aí que repousa a relação essencial entre 'questionar' e 'saber'." 39 . A natureza do saber é dialéctica e fundamenta o procedimento dialéctico como o perguntar no qual o saber se constitui à medida da eliminação de outro saber que só assim se revela falso, quer dizer, pela própria actividade questionante. A estrutura do diálogo é a estrutura do próprio pensar e nesta medida do próprio saber. Ao tomar a dialéctica platónica como modelo, Gadamer não faz senão considerar que só no intercâmbio pergunta-resposta há saber. Tomando esta posição na radicalidade das suas implicações, isto significa que a verdade não está nem antes nem fora do diálogo, no sentido de não haver um saber prévio com o qual se inicia o diálogo, nem um saber "fora" como objecto do saber.

A crítica à ideia de método por parte de Gadamer, deve inclusivamente ser enquadrada na sua concepção de saber que se define como questionabilidade e abertura de possibilidades, e não apenas na perspectiva de uma conduta alienante que pretende romper com a condição ontológica de pertença. É no entanto este último aspecto que é registado por Ricœur e daí a interpretação que sugere do título da obra de Gadamer: Verdade ou Método em vez de Verdade e Método.

A dialéctica que Gadamer toma como referência e modelo é a dialéctica platónica, em oposição expressa à dialéctica hegeliana. Em Wahrheit und Methode, em Epílogo, afirma de um modo claro: “... a minha intenção foi

38 "One important aspect of discourse is that it is addressed to someone. There is another speaker who is the addressee of the discourse. The presence of the pair, speaker and hearer, constitutes language as communication. The study of language from the point of view of communication does not begin with the sociology of communication, however. As Plato says, dialogue is an essential structure of discourse." RICOEUR, Interpretation theory, pp. 14-15.

39 GADAMER, Wahrheit und Methode, trad. castelhana, p. 442. 
reunir a dimensão da hermenêutica filosófica com a dialéctica platónica, não com a hegeliana"40. Gadamer, intérprete de Platão, compreende e unifica o método dialéctico no primeiro e último Platão e formula uma concepção de dialéctica que permanece do princípio ao fim "arte do diálogo"41. A dialéctica hegeliana não está ligada ao sentido de dialéctica como "arte do diálogo" que é o que nos importa reter na hermenêutica; o termo dialéctica utilizado por Hegel, como afirma Gadamer, "vem em verdade, não da génese da dialéctica a partir do diálogo, mas do pensamento por contradições" 42 .

Diferentemente do que lemos em Gadamer, o conceito de dialéctica é utilizado frequentemente no texto de Ricœur num sentido hegeliano, de valorização do conflito, da contradição e dos opostos num processo de mediação reflexiva ${ }^{43}$. Assim, a título de exemplo, vemos que o discurso é dialéctico a diversos níveis (evento/significação e sentido/referência), a relação explicar-compreender é dialéctica, a actividade de leitura é dialéctica. Neste último caso, afirma Ricœur: "Podemos, enquanto leitor, permanecer na suspensão do texto, tratá-lo como texto sem mundo e sem autor; enquanto o explicamos pelas suas relações internas, pela sua estrutura. Ou então podemos levantar a suspensão do texto, realizar o texto em palavras, restituindo-o à comunicação viva; então nós interpretamos. Estas duas possibilidades pertencem ambas à leitura e a leitura é a dialéctica destas duas atitudes" 44 . Como dirá significativamente em "Mimesis, référence et réfiguration": "Podemos falar de dialéctica na medida em que o fenómeno chamado leitura pode ser aproximado por dois lados opostos" 45 .

A unidade do saber e da hermenêutica - dissociada da possibilidade de um saber absoluto e de uma mediação total - parece estar associada a uma

40 GADAMER, Wahrheit und Methode, trad. castelhana, p. 649.

41 Gadamer, "Dialectic and Sophism in Plato's seventh Letter" in Dialogue and Dialectic, trad. de C. Smith, Yale University Press, London 1980, p. 122.

42 GADAMER,Platos dialektische Ethik, Felix Meiner Verlag, Hamburg 1968,pp. 221-247, tradução francesa "Dialectique et sophistique dans la VII lettre de Platon", in Art de Comprendre. Écrits I. Herméneutique et tradition philosophique, Éditions Aubier Montaigne, Paris, 1982, p. 122.

43 "Par dialectique, j'entends la considération selon laquelle expliquer et comprendre ne constitueraient pas les pôles d'un rapport d'exclusion, mais les moments relatifs d'un processus complexe qu'on peut appeler interprétation." RICCEUR, Du texte à l'action, p. 162.

44 "Nous pouvons, en tant que lecteur, rester dans le suspens du texte, le traiter comme texte sans monde et sans auteur; alors nous expliquons par ses rapports internes, par sa structure. Ou bien nous pouvons lever le suspens du texte, achever le texte en paroles, le restituant à la communication vivante; alors nous l'interprétons. Ces deux possibilités appartiennent toutes les deux à la lecture et la lecture est la dialectique de ces deux attitudes." RICCEUR, Du texte à l'action, pp. 145-146.

45 "Nous pouvons parler de dialectique dans la mesure ou le phénomène appelé lecture peut être approché par deux côtés opposés." RICCEUR, "Mimèsis, référence et refiguration dans Temps et récit" in Études phénoménologiques, Tomo VI, 1990, n. ${ }^{\circ} 11$, p. 39. 
perspectiva de contradição e unidade dos opostos, e o todo ao concreto na unidade e riqueza das suas múltiplas determinações, que a filosofia reflexiva articula. Sem qualquer hipótese de saber absoluto, a dialecticidade do saber parece ter como consequência a recusa de toda a unilateralidade (insuficiente e abstracta) e o reconhecimento da historicidade da consciência num processo em que forma e conteúdo, ser e saber, não coincidem nunca. O sujeito humano continua a ser o lugar da consciência de si, de um "si" que se conhece reflexivamente e mediatamente através dos textos que lê e das obras que realiza. A dialéctica liga-se deste modo à reflexividade do saber de si como consciência de unidade. O processo interpretativo é, em qualquer circunstância, o percurso pelo qual a reflexão se torna concreta, ultrapassando pọr esta via "a abstracção vã e vazia do "eu penso"" e retomando em si "os signos opacos, contingentes e equívocos que estão esparsos nas culturas em que a nossa linguagem se enraiza" ${ }^{4}$. Se bem que esta afirmação apareça no contexto da definição da tarefa interpretativa pela decifração da expressões de duplo sentido ou simbólicas, no entanto, a sua validade não se restringe a este momento: não só porque a hermenêutica textual não contradiz a hermenêutica dos símbolos, como a reflexão permanece do princípio ao fim o pressuposto da filosofia e da hermenêutica e a tarefa do sujeito (sentido ético). Na ausência de intuição e de fundamento último o sujeito só se reapodera de si através do desvio das interpretações. ${ }^{47}$

O texto integra a dialéctica entre a compreensão e a explicação e, concebido como mediação para a compreensão de si, é mediação entre o ego e o

46 "Telle est l'ultime racine de notre problème: elle réside dans cette connexion primitive entre l'acte d'exister et les signes que nous déployons dans nos oeuvres; la réflexion doit devenir interprétation, parce que je ne peux saisir cet acte d'exister ailleurs que dans des signes épars dans le monde. C'est pourquoi une philosophie réflexive doit inclure les résultats, les méthodes et les présuppositions de toutes les sciences qui tentent de déchiffrer et d'interpréter les signes de l'homme. Telle est dans son principe et dans sa plus grande généralité la racine du problème herméneutique. Il est posé d'une part par l'existence de fait du langage symbolique qui fait appel à la réflexion, mais aussi en sens inverse, par l'indigence de la réflexion qui fait appel à l'interprétation: en se posant elle-même, la réflexion comprend sa propre impuissance à dépasser l'abstraction vaine et vide du 'je pense' et la nécessité de se recouvrer elle-même en déchiffrant ses propres signes perdus dans le monde de la culture. Ainsi la réflexion comprend elle-même qu'elle n'est pas d'abord science, qu'il faut, pour se déployer, reprendre en elle-même les signes opaques, contingents et équivoques qui sont épars dans les cultures où notre langage s'enracine" RICCEUR, De l'interprétation p. 54.

47 Como reafirmará Ricoeur no prefácio de Soi-même comme un autre (1990), depois de apresentar um resumo dos estudos que compõem esta obra: "Le survol qu'on vient de proposer des études qui composent cet ouvrage donne une première idée de l'écart qui sépare l'herméneutique du soi des philosophies du Cogito. Dire soi, ce n'est pas dire je. Le je se pose - ou est déposé. Le soi est impliqué à titre de réfléchi dans des opérations dont l'analyse précède le retour vers lui-même. Sur cette dialectique de l'analyse et de la réflexion se greffe celle de l'ipse et de l'idem. Enfin, la dialectique du même et de l'autre couronne les deux premières dialectiques." RICCEUR, ob cit., p. 30. 
soi. É alicerçado no conceito de leitura concebido dinamicamente como efectuação da significação do texto que Ricoeur une a explicação e a compreensão, o sentido e a referência: é "no próprio coração da leitura que indefinidamente, se opõem e se conciliam explicação e interpretação" (sublinhado nosso $)^{48}$. A actividade da leitura levada a cabo por um leitor/sujeito permite actualizar as possibilidades que derivam do estatuto do texto: rede de relações de sentido e projecção de um mundo. A leitura realiza a dialéctica da interpretação como dialéctica entre compreensão e explicação e nesta medida, realiza (concretiza e actualiza) a verdade do texto.

Considerar o processo interpretativo na sua unidade dialéctica (compreensão /explicação) tem como condição separar a compreensão e a interpretação do contexto dialogal: "Há uma dialéctica entre explicar e compreender porque o par escrever-ler desenvolve uma problemática própria que não é só uma extensão do par falar-ouvir constitutivo do diálogo"49. Em Interpretation theory e em Du texte à l'action a interpretação é colocada sob o "paradigma da leitura". O paradigma da leitura é o que Ricœur opõe ao "paradigma do diálogo" na hermenêutica. E se "a relação dialogal não nos fornece o paradigma da leitura é preciso construir este último como um paradigma original, como um paradigma próprio" 50 porque, afirma Ricœur de um modo incisivo em Interpretation theory: "A hermenêutica começa quando o diálogo acaba"'51. É porque os textos são, desde o início, "escrita", que exigem a leitura como restabelecimento da dimensão comunicativa do discurso; e é o facto de não pertencerem a um contexto de comunicação presencial que define o seu estatuto textual. É também por esse motivo, por exemplo, que os mitos dissociados do contexto do seu ritual e perdendo o seu poder interveniente, podem ser considerados textos, quer dizer, uma escrita separada da sua pertença ao discurso, ao discurso significante da humanidade ${ }^{52}$.

48 "C'est au cœur même de la lecture que, indéfiniment, s'opposent et se concilient l'explication et l'interprétation" RICCEUR, Du texte à l'action, p. 159.

49 "Il y a une dialectique entre expliquer et comprendre parce que le couple écrire-lire développe une problématique propre qui n'est pas seulement une extension du couple parler-entendre constitutif du dialogue" RICEEUR, Du texte à l'action, p. 198.

50 "Si donc la relation dialogale ne nous fournit pas le paradigme de la lecture, il faut construire ce dernier comme un paradigme originel, comme un paradigme propre." RICCEUR, Du texte à l'action, p. 199.

51 "This opportunity for multiple readings is the dialectical counterpart of the semantic autonomy of the text.

It follows that the problem of the appropriation of the meaning of the text becomes as paradoxical as that of the authorship. The right of the reader and the right of the text converge in an important struggle that generates the whole dynamic of interpretation. Hermeneutics begins where dialogue ends." RICEUR, Interpretation theory, p. 32.

52 Afirma Ricoeur, comentando o conceito de "lei estrutural", a partir da análise do mito de Édipo por Lévi-Strauss: "On ne manquera pas de noter que cette loi est, par excellence, objet de lecture et pas du tout de parole, au sens d'une récitation où le pouvoir du mythe 


\section{§ 4. A substituição do diálogo pela leitura}

A ligação texto-escrita-leitura afastando a interpretação do modelo dialogal permite, segundo Ricœur, a integração de leituras diversas no mesmo processo interpretativo, no mesmo "arco hermenêutico". A autonomia e plurivocidade do texto abrem-no a um conjunto de leituras legítimas; a leitura estrutural é uma dessas leituras que tem inclusivamente por função possibilitar a compreensão hermenêutica de nível superior.

Ao introduzir o paradigma da leitura, Ricœur torna mais coesa a sua teoria do texto dado que é a leitura que responde directamente ao seu carácter escrito e que se incorpora à sua realidade textual de modo que a "relação entre tradição e interpretação é uma relação interna ao texto" 53 . Se existe um "mundo do texto" como o que corresponde à sua referência, esse mundo só se revela pelo acto de leitura concebido como acto de aplicação, através do qual "a literatura retorna à vida" 54 . Se o conceito de "paradigma da leitura" parece situar-se principalmente a nível epistemológico à época de $D u$ texte à l'action numa relação directa e imediata com a expressão "paradigma textual", o desenvolvimento de uma teoria da leitura em Temps et Récit (momento da mimesis III), o esclarecimento do seu papel mediador na determinação da referência textual ${ }^{55}$ a par de uma maior precisão do conceito de "mundo do texto", permitirão dar-lhe um maior alcance. O leitor é não só um intérprete, mas também um sujeito, uma consciência e um agente. Vemos que na categoria hermenêutica da leitura Ricœur faz trabalhar as categorias filosóficas da ordem da ontologia (intérprete /Dasein), da filosofia reflexiva (sujeito / auto-conhecimento), da ética (agente / interveniente). A leitura deve ser entendida como actividade, como resposta do leitor ao texto, mas nessa resposta está implicada uma consciência que reflecte e reelabora o "mundo" e se predispõe a agir.

sera réactivé dans une situation particulière. Ici le texte n'est que texte et la lecture ne l'habite qu'en tant que texte, dans le suspens de sa signification pour nous, dans le suspens de toute effectuation dans une parole actuelle." RICEEUR, Du texte à l'action, p. 149.

53 “... la relation entre tradition et interprétation est une relation interne au texte; interpréter, pour l'exégète, c'est se mettre dans le sens indiqué par cette relation d'interprétation portée par le texte lui-même. RICCEUR, Du texte à l'action, p. 156.

54 “C'est à travers la lecture que la littérature retourne à la vie, c'est à dire au champ pratique et pathique de l'existence. C'est donc sur le chemin d'une théorie de la lecture que nous cherchons à déterminer la relation d'application que constitue l'équivalent de la relation de répresentance dans le domaine de la fiction". RICEEUR, Temps et récit III, p. 149.

55 Aspecto que Ricœur considera ter-lhe "escapado" em La Métaphore Vive: "Dans Temps et récit, la transition entre configuration et refiguration est préparée et construite à travers une séquence soigneuse d'étapes. (...) Finalement, Mimèsis III designe l'équivalent narratif de la refiguration du réel par la métaphore. Je souligne aussi avec grande précision le rôle médiateur exercé en ce point par la lecture, point qui m'avait échappé dans La Métaphore vive." RICEEUR, "Mimèsis, référence et refiguration dans Temps et récit" in Études phénoménologiques, Tomo VI, 1990, n.ำ11, pp. 31-32. 
À medida que o conceito de sujeito aparece perspectivado eticamente e que a reconstrução do passado histórico se aproxima do "como se" ficcional em Temps et récit, verificamos que Ricœur se afasta do vocabulário da referência que dominou La Métaphore Vive para desenvolver uma teoria da leitura incluída na "operação de refiguração", e submetida tanto à "dialéctica distanciação-apropriação" como à dialéctica mais englobante do "Mesmo, do Outro, do Análogo" no âmbito de uma consciência histórica. A questão do "mundo da obra" (a sua referência) aparece perspectivada em Temps et récit de um modo diferente em relação às obras anteriores: o ponto de partida é o da leitura e do sujeito e não tanto o do texto. Quer dizer, a tónica é a do presente e da acção. Nesta medida é principalmente a leitura que aparece como mediação - para a acção - e é o conceito de leitura/legibilidade que permite articular a "análise textual, o conhecimento histórico e a teoria da acção" 56 . A circunscrição da hermenêutica ao texto revela-se agora de pesadas consequências tanto do ponto de vista epistemológico, como ontológico e existencial, por intermédio do conceito correlativo de leitura.

A questão da significação dos textos sofre uma deslocação, passando a ser fundamentalmente equacionada não tanto em termos de "projecção de um mundo" mas em termos de operação de "refiguração"; quer dizer, não em termos de "referência", mas em termos de leitura, apropriação e aplicação. Do ponto de vista do sujeito, a leitura é apenas um meio que atravessa: “(...) enquanto que o leitor incorpora - conscientemente ou inconscientemente, pouco importa - os ensinamentos das suas leituras à sua visão do mundo, a fim de lhe aumentar a legibilidade prévia, a leitura é para ele outra coisa mais do que um meio onde se detém; ela é um meio que ele atravessa" 57 .

A impossibilidade do texto se esgotar em uma leitura ${ }^{58}$ (quer nos situemos numa perspectiva sincrónica ou diacrónica) parece fazer romper o paradigma da escrita e do texto. Parece ser fora do texto, tanto na experiência do autor primeiramente, como na experiência do leitor posteriormente, que a significação emerge se bem que difusa e não codificada. O "trabalho" da

56 Afirma Ricœur que o pôr em paralelo a "análise textual, o conhecimento histórico e a teoria da acção" só é possível porque se começa por circunscrever a hermenêutica ao texto, que "contém o princípio de ultrapassagem de todos os domínios limitados tomados por ponto de partida" (RICEUR, "Logique herméneutique" in Contemporany Philosophy. A new survey. Haia/Boston/ Londres, M.Nijhoff, 1981, p. 199.

57 “(...) en tant que le lecteur incorpore - consciemment ou inconsciemment, peu importe les enseignements de ses lectures à sa vision du monde, afin d'en augmenter la lisibilité préalable, la lecture est pour lui autre chose qu'un lieu où il s'arrête; elle est un milieu qu'il traverse" RICEUUR, Temps et récit III pp. 263-264.

58 "Tout texte, fût-il systématiquement fragmentaire, se révèle inépuisable à la lecture, comme si, par son caractère inéluctablement sélectif, la lecture révélait dans le texte un côté non écrit. C'est ce côté que, par privilège, la lecture s'efforce de se figurer. Le texte paraît ainsi tour à tour en défaut et en excès par rapport à la lecture." RICEUR, Temps et récit III, p. 247. 
escrita na composição dos textos, o seu resultado na obra produzida, faz desta apenas a mediação necessária, o material a partir do qual o "trabalho" da leitura interpretativa constrói a significação adequada à experiência do leitor. Esta experiência não deve ser entendida num sentido exclusivamente individual mas também histórico. É aliás esta possibilidade de transformar o indizível no dizível, o particular no universal, o individual no histórico, que faz das obras a mediação na comunicação humana ${ }^{59}$. É fora das obras e, no entanto, através delas que a significação se constrói e que o sujeito pode aceder a uma consciência de si como ser individual, histórico e práxico. Neste sentido, também o autor pode ser considerado como intérprete e como sujeito: porque não escapa à situação hermenêutica e porque o trabalho de produção de uma obra é praxis que o implica como agente (da obra e de si próprio).

A "renúncia a Hegel" faz-se através de uma teoria da consciência histórica e pela recusa da mediação total ${ }^{60}$. Mas se a reflexão não pode coincidir nunca com o seu objecto, é no trabalho produtivo com essa distância que a consciência pode ser "de si para si", uma consciência apenas humana que se reconhece nas suas obras, particularmente as da linguagem. O poder refigurante do texto torna-se operativo na acção efectiva. Este agir efectivo parece referir-se fundamentalmente a um sentido ético que transforma o mundo na medida em que transforma o sujeito. Em última análise é este o critério que orienta toda a investigação de Ricœur, para o qual aponta como a "flecha de sentido", o "horizonte" de inteligibilidade da sua própria obra. É um sujeito transformado pelas leituras que lhe revelaram novas possibilidades de ser, que se conhece melhor porque aceitou desapossar-se do seu ego narcísico, que acaba por emergir. Os textos, as obras, a leitura, não são senão o desvio do acesso do sujeito a si próprio: do ego ao soi. A teoria hermenêutica como teoria da interpretação intervém apenas acompanhando este percurso e também ela é, em Ricœur, apenas mediação para uma nova hermenêutica da temporalidade e da ipseidade.

É pela leitura que vemos o conceito de sujeito intervir directamente no fenómeno hermenêutico. O sujeito intervém a título de intérprete passivo, quer dizer, submetido à história dos efeitos; a título de intérprete que conduz

59 Afirma Ricoeur em Interpretation theory: "To conclude this discussion of the dialectic of event and meaning, we may say that language is itself the process by which private experience is made public. Language is the exteriorization thanks to which an impression is transcended and becomes an ex-pression, or, in other words, the transformation of the psychic into the noetic. Exteriorization and communicability are one and the same thing for they are nothing other than this elevation of a part of our life into the logos of discourse. There the solitude of life is for a moment, anyway, illuminated by the common light of discourse." RICEUR, Interpretation theory, p. 19.

60 "Renoncer à Hegel" é o título do capítulo 6 de Temps et récit III.Cf. RICCEUR, Temps et récit III, pp. 280-299. 
a exegese e participa activamente na construção da significação; a título de sujeito da apropriação, aquele para quem o texto se constitui como projecto de apropriação pessoal e que é transformado pela leitura enquanto sujeito ético. $\mathrm{O}$ conceito de leitura revela o fenómeno hermenêtico em toda a sua extensão e permite, de um modo coerente, a transição da hermenêutica textual para a hermenêutica do soi tal como vemos constituir-se em Soi même comme un autre 61 .

A teoria da leitura e a consideração do seu papel de mediação na refiguração do real (mimesis III), não representa apenas mais um elemento acrescentado à teoria do texto. A teoria da leitura está acompanhada de um nova definição de texto - texto enquanto configuração - que representa uma conceptualização superior e integradora relativamente ao conceito de texto autónomo e plurívoco. A configuração textual também pode ser considerada abstractamente fora das suas relações com o "montante" e o "jusante" do texto. Mas a integração da configuração textual como o segundo momento da mimesis, e a hermenêutica concebida como dizendo respeito ao processo inteiro da mimesis, inclui de um modo orgânico o autor e o mundo prático, a obra como resultado de um trabalho de composição e a leitura como o momento da recepção da obra, constituinte da significação e a partir do qual o leitor /sujeito refigura o mundo e se transforma. $\mathrm{O}$ acto de leitura constitui afinal "o medium decisivo graças ao qual os leitores começam a 'ler neles próprios" "62...A leitura não será senão um momento no processo de interpretação de si e na constituição do si. A hermenêutica textual não será também, na obra de Ricœur, senão transição para uma hermenêutica do si.

A obra de Ricœur Soi même comme un autre, constitui para nós principalmente a obra-referência que permite uma perspectiva integradora da sua hermenêtica; aquela que melhor nos permite compreender o conceito que consideramos angular e que acaba por estabelecer uma unidade última em todo o seu pensamento: o de sujeito. Tematizado no âmbito de uma ontologia, de uma ontologia da ipseidade, permite melhor compreender a preocupação que anima toda a obra de Ricœur: a preocupação com o sujeito ético, com o sujeito da acção. O contributo de Ricœur para a hermenêutica enquanto teoria da interpretação - estamos a pensar nomeadamente na resolução da oposição entre explicar e compreender - se se pode pensar de modo relativamente independente não se pode no entanto desligar dos seus pressupostos filosóficos e do conjunto da sua obra. É a teoria da leitura que estabelece a transição entre uma hermenêutica textual e uma hermenêutica do si (soi). Mas ao mesmo tempo que a hermenêutica textual é integrada numa herme-

61 RICCEUR, Soi-même comme un autre, Éditions du Seuil, Paris, 1990.

62 “....l'acte de lecture constitue selon moi le medium décisif à la faveur duquel les lecteurs commencent à 'lire en eux-mêmes'," RICEEUR, "Mimèsis, référence et réfiguration en Temps et récit”, ob.cit., p. 40. 
nêutica da ipseidade, a constitução da ipseidade revela-se ser também "hermenêutica". A constituição do si é hermenêutica porque a relação de si a si é uma relação mediata (não há intuição); porque a distância continua a ser condição de toda a significação. O sentido advém à consciência através da leitura interpretativa e uma "vida examinada" é uma vida "interpretada": a reflexão apenas se concebe sob a forma da interpretação. Não só as obras dão um si ao ego, como afirmava Ricoeur em Le conflit des interprétations, mas é o próprio si que se concebe como obra. E se não somos os autores da nossa vida, somos no entanto autores da nossa história; não no sentido do domínio sobre os elementos factuais, mas na capacidade da leitura que transforma os acontecimentos em história. É por isso que, sendo a narratividade a forma de organização da experiência temporal, o texto narrativo é privilegiado do ponto de vista da hermenêutica de Ricœur e perspectiva-se duplamente: como "solução" poética para o problema do tempo e como modelo da "identidade narrativa".

Considerando que a interpretação deve ser referida ao processo interpretativo pelo qual o sujeito se reapodera de si, a expressão "paradigma da leitura" utilizada em Du texte à l'action e em Interpretation theory, pode ser alargada e cobrir tanto a hermenêutica textual como a hermenêtica do soi. A oposição entre o modelo da leitura e o modelo dialogal não é uma oposição de circunstância: é nela que se perspectiva a opção de fundo de Ricœur em constituir não apenas uma teoria hermenêutica mas uma filosofia hermenêutica em que o sujeito e a reflexão são sempre o que está em causa.

Por outro lado a hermenêutica em Ricœur deve ser concebida na forma de uma hermenêutica geral, quer dizer, de uma hermenêutica que dê conta do fenómeno da interpretação nas suas múltiplas acepções e nos seus diversos campos (incluindo a hermenêutica bíblica). Para Ricœur, o paradigma do diálogo na hermenêutica não só seria limitativo e correria o risco de queda no psicologismo, como não parece corresponder àquilo que primeiramente se exige na atitude do leitor que quer compreender o texto: uma atitude receptiva de modo a poder ser "formado" e "transformado"63. A leitura estará, antes do mais, ligada à receptividade obediente (no sentido etimológico de "prestar ouvido atento, escutar") da escuta, a partir da qual o sujeito transforma a sua acção e se transforma a si próprio ${ }^{64}$.

63 “Notre herméneutique générale nous invite à dire, que l'étape nécessaire entre l'explication structurale et la compréhension de soi, c'est le déploiement du monde du texte; c'est lui qui finalement forme et transforme selon son intention l'être-soi du lecteur." RICCEUR, $D u$ texte à l'action, p. 126.

64 "...comprendre, c'est se comprendre devant le texte. Non point imposer au texte sa propre capacité finie de comprendre, mais s'exposer au texte, et recevoir de lui un soi plus vaste, qui serait la proposition d'existence répondant de la manière la plus approprié à la proposition de monde" (sublinhado nosso) RICEUR, Du texte à l'action, p. 116-117. 


\section{Conclusão}

A limitação do conceito de diálogo à situação oral e a ausência no texto de Ricœur de um verdadeiro debate com Gadamer quanto à estrutura dialógica do fenómeno hermenêutico, poderão ser interpretadas como sinal de uma profunda divergência entre as duas hermenêuticas que aí se deixa ver: o que o texto explicitamente diz reveste-se de tanta importância quanto o que não diz.

Se a recusa do modelo dialogal é, de um modo explícito, a recusa da hermenêutica romântica, ela revela ser também, de um modo implícito, o afastamento relativamente à hermenêutica de Gadamer e a valorização da dimensão reflexiva e do alcance ético da actividade hermenêutica.

A análise dos modos diferentes de conceber o diálogo e do seu papel do ponto de vista hermenêutico nos dois autores, acaba por evidenciar que o esquecimento que o texto de Ricoeur patenteia, a este nível, relativamente à perspectiva gadameriana, revela, afinal, os pressupostos, filiações e finalidades da sua hermenêutica.

\section{Abstract}

Every philosophy has a conceptualisation which demarcates it and defines a net of signification, even in the field of filiation or proximity relations. Ricœur's hermeneutics is admittedly close to Gadamer's hermeneutics, due to the aim of integrating and rectifying it and to its identical or equivalent conceptualisation (in some cases). My topic concerns the difference between the two hermeneutics, which mainly emerges through the relevance attached to dialogue. The chief question I ask is whether that difference is insignificant and sporadic or, in contrast, is determinant to the description of Ricœur's hermeneutics, which would mark it out against Gadamer's. The former establishes a link between dialogue and oralism, which allow us a coherent understanding of not only his opposition to romantic hermeneutics, but also the development of his epistemological project. By analysing these matters we will, therefore, realise the consistency of the hermeneutic paradigm put forward by Ricœur, as well as the progressively clear cut between the two hermeneutical models. 